\title{
Articular manifestations in Egyptian children with familial Mediterranean fever
}

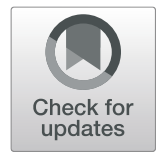

\author{
Yomna Farag ${ }^{*}$ (D), Heba Taher, Noha Mostafa Seleem, Diana Fahim and Huda Marzouk
}

\begin{abstract}
Background: Familial Mediterranean fever (FMF) is an autosomal recessive auto-inflammatory disease. Arthritis in early-onset FMF is a common finding. The aim of this study was to assess frequency of arthritis in 200 Egyptian children with FMF and also to detect its clinical characteristics, response to colchicine treatment, its effect on disease severity, and the most common MEFV gene mutations in patients with arthritis.

Results: We studied 200 children with FMF. We analyzed joint involvement in FMF attacks regarding its clinical characteristics, its effect on the disease severity, and response to colchicine treatment. We found arthritis in 20.5\% of the studied population. Most of the children with arthritis had mono-articularjoint involvement during the FMF attack (73.1\%), followed by oligo-articularjoint (22\%). The knees and ankles were the most commonly affected joints. Arthritis was the presenting symptom in only $4 \%$. We observed redness of the affected joints in $70.7 \%$, and persistence of swelling after the attacks only in $17.1 \%$. The majority of patients (85.4\%) had a $75-100 \%$ decrease in the frequency of arthritic attacks after colchicine treatment. We did not find any joint disability in all studied patients, and arthritis was only present during attacks. The most frequent MEFV gene mutations in arthritic patients wereV726A and E148Q, each occurring in 28.6\%. We observed an earlier age of disease onset and a more disease severity in patients with arthritis ( $p=0.031$ and $p \leq 0.001$, respectively). We also observed that chest pain, erysipelas-like-erythema, and testicular affection were more observed in patients with arthritis ( $p$ values $0.001,0.001$, and 0.006 , respectively).
\end{abstract}

Conclusion: This study showed that around 20\% of Egyptian children with FMF can develop arthritis during the attacks, which usually runs a benign course. The presence of arthritis can denote a more severe disease course.

Keywords: FMF, Arthritis, MEFV gene mutation

\section{Keypoints}

Articular manifestations in FMF children, severity, and scoring of FMF in FMF children with arthritis

\section{Background}

Familial Mediterranean fever is an autosomal recessive disorder recently considered as one of the monogenic auto-inflammatory diseases [1]. It is caused by mutation in MEFV gene [2], one of the genes encrypting proteins important for regulation of innate immune system [3-6].

\footnotetext{
*Correspondence: yomnafarag@yahoo.com; yomna.farag@kasralainy.edu.eg Department of Pediatric Rheumatology, Faculty of Medicine, Cairo University, Cairo, Egypt
}

\section{Springer Open}

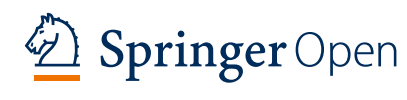

It is a periodic fever syndrome characterized by recurrent attacks of fever with healthy interval in-between episodes [4]; these episodes are also associated with inflammation in different parts of the body as pleuritis, arthritis, pericarditis, peritonitis, and orchitis. Attacks last for 2 or 3 days and complete recovery is usual but with recurring episodes of arthritis [1].

The classical presentation is of acute joint involvement precipitated by minor trauma or effort. It is usually selflimiting mono arthritis affecting the shoulders, hips, knees, temporomandibular, or sternoclavicular joints $[1$, 5, 7]. The articular involvement usually starts at an early age and is usually short in duration. The joint becomes red, hot, and swollen with a limitation of movement.

(c) The Author(s). 2020 Open Access This article is licensed under a Creative Commons Attribution 4.0 International License, which permits use, sharing, adaptation, distribution and reproduction in any medium or format, as long as you give appropriate credit to the original author(s) and the source, provide a link to the Creative Commons licence, and indicate if changes were made. The images or other third party material in this article are included in the article's Creative Commons licence, unless indicated otherwise in a credit line to the material. If material is not included in the article's Creative Commons licence and your intended use is not permitted by statutory regulation or exceeds the permitted use, you will need to obtain permission directly from the copyright holder. To view a copy of this licence, visit http://creativecommons.org/licenses/by/4.0/. 
Complete resolution of symptoms usually occurs with resolution of the attack [8]. These symptoms occur due to influx of neutrophils into the affected tissue due to uninhibited pyrin activity resulting in uncontrolled production of interleukin-1 [9-11].

It was observed that articular attacks affect up to three quarters of patients with FMF, and sometimes it is the sole manifestation in up to $15 \%$ of patients [12-14]. Sometimes patients are misdiagnosed as juvenile idiopathic arthritis or acute rheumatic fever due to an early age of onset and high frequency of arthritis or arthralgia [12-14]. Careful and accurate assessment of signs and symptoms is essential for early detection and differential diagnosis of FMF.

Musculoskeletal involvement in FMF, mostly in the form of arthritis or arthralgia, is the third common manifestation, following periodic fever and abdominal pain [15]. The frequency of arthritis in FMF has been reported to range from 21 to $77 \%$ in different ethnic groups [15-17]. Classically, the presentation is recurrent mono-articular joint involvementat early age, usually between 1 and 5 years $[15,16]$. Arthritis in FMF usually responds to colchocine. Resistent cases can be given methotrexate and anti-tumor necrosis factor biologics (etanercept and infliximab) [18].

The purpose of this study was to assess frequency of arthritis in 200 Egyptian children with FMF and also to detect its clinical characteristics, response to colchicine treatment, its effect on disease severity, and the most common MEFV gene mutations in patients with arthritis.

\section{Methods}

This was a retrospective study, and 200 children were included who were diagnosed as FMF according to the new pediatric FMF criteria [19]. They were being followed in our pediatric rheumatology clinic, from March 2017 to September 2019. All included patients were diagnosed with FMF before age of 18 years, and we included FMF patients whether in attack or in between attacks (at least 2 weeks after the last attack). Children with any associated autoimmune disease were excluded.

Informed consents were taken from the parents or the patient's guardians.

Demographic data was collected from patients' files (age, sex, and consanguinity; family history of FMF; and family history of autoimmune diseases). Clinical history including age at onset and at diagnosis, disease duration, number of attacks/year, and duration of attack before starting treatment and at the time of study was recorded. Disease symptoms (fever, abdominal pain, chest pain, arthritis, erysipelas-like rash, orchitis, and vasculitis) were reported. Also dose of colchicine at the time of the study was reported. We also recruited investigations done at disease onset as follows: complete blood count, erythrocyte sedimentation rate, C-reactive protein, proteinuria, and results of MEFV gene mutations. Plain $\mathrm{X}$-ray was done for all patients with arthritis to detect anyerosion.

Disease severity was measured by severity score $[1=1$ site in single attack, $2=2$ sites in disease course, $3=2$ $\mathrm{mg}$ of colchicine to achieve remission, $4=2$ pleuritic attacks in disease course, $5=2$ erysiple-like erythemaattacks in disease course, $6=$ age of onset $<10$ years "interpretation" severe disease $=3$ criteria, intermediate $=2$ criteria, mild = 1 criterion] [20] and response to colchicine therapy assessed by FMF- 50 score [which assess the response to treatment using the following: 1-change in frequency of attacks, 2-change in duration, 3-patients/ parents global assessment, 4-physician global assessment, 5-change in arthritis attack, and 6-change in inflammatory markers. At least $50 \%$ improvement in five out of six criteria by 3 to 6 months means FMF 50 response [2].

Analysis of joint involvement was done regarding (age at onset, arthritis as presenting symptom, duration of attack of arthritis/hour, and number of swollen joint either monoarticular (1 joint), oligoarticular (2-4 joints), or polyarticular ( $>4$ joints), type of affected joint, clinical picture (redness, limitation of movement, relation to fever, persistence of swelling after the attack, complete resolution or chronic limitation, response of arthritis after 6 months of colchicine treatment, and use of other DMARDS). Then patients were divided into 2 groups according to the presence of arthritis [group 1: patients with arthritis $(N=41)$ and group 2: patients without arthritis $(n=159)]$; the two groups were statistically compared regarding previous data collected.

\section{Statistical methods}

Data were coded and entered using the statistical package SPSS (Statistical Package for the Social Sciences) version 24. Data was summarized using the mean, standard deviation, median, minimum, and maximum in quantitative data and using frequency (count) and relative frequency (percentage) for categorical data. Comparisons between quantitative variables were done using the non-parametric Mann-Whitney test [21]. For comparing categorical data, chi-square $\left(\chi^{2}\right)$ test was performed. Fisher's exact test was used instead when the expected frequency is less than 5 [22]. $P$ values $\leq 0.05$ were considered as statistically significant.

\section{Results}

Two hundred patients were included in this study; 96 were males (48\%) and 104 were females (52\%). Demographic features of the studied FMF patients were summarized in Table 1. 
Table 1 Demographic features of studied FMF patients according to age, family history, consanguinity, disease duration and arthritis

\begin{tabular}{ll}
\hline Patients' characteristics & $\begin{array}{l}\text { Frequency }(\boldsymbol{n}=\mathbf{2 0 0}) / \\
(\text { mean } \pm \text { SD) }\end{array}$ \\
\hline Consanguinity & $68(34 \%)$ \\
Family history of FMF* & $76(38 \%)$ \\
Family historyof autoimmune diseases & $26(13 \%)$ \\
Age at time of study (years) & $9.98 \pm 3.48$ \\
Age at onset of disease (years) & $4.44 \pm 2.86$ \\
Age at diagnosis (years) & $6.25 \pm 3.07$ \\
Disease duration (years) & $5.54 \pm 3.19$ \\
Arthritis as a presenting symptom & $8(4 \%)$ \\
\hline
\end{tabular}

*FMF familial Meditarranean fever

Observing the genotypic features of studied FMF patients revealed that 127patients (63.5\%) had heterozygous gene mutation, 27 patients (13.5\%) had homozygous gene mutation, and 30 patients (15\%) had compound heterozygous gene mutation, while negative gene mutation was recorded in 16 patients $(8 \%)$. The type of MEFV gene mutation of included FMF patients was summarized in Table 2. All X-rays that were done did not show any erosions.

Patients were divided into two groups according to the presence of arthritis in their disease course. Group 1: FMF patients having arthritis $(n=41)$ and group 2: FMF patients without arthritis $(n=159)$. Table 3 showed the comparison between group 1 and group 2 patients as regards demographic features. We found that the mean age of the patients at the time of the study in the arthritic group was statistically significantly higher, while the mean age of FMF onset was significantly lower in the arthritic group and the mean disease duration was significantly longer in the arthritic group $(p=0.023,0.031$, $<0.001$, respectively) (Table 3 ).

Table 4 showed the comparison between the previous two groups regarding clinical manifestations of FMF attacks, laboratory parameters at time of disease, and colchicine dosage at the time of the study. We observed that chest pain, erysipelas-like erythema, and testicular affection more in patients were arthritis, with a statistical significance difference ( $p$ values $0.001,0.001$, and 0.006 , respectively). Also, ESR was higher in patients with arthritis ( $p$ value 0.02$)$.

Table 2 Type of MEFV gene mutation of included FMF patients ( $n$-230), pattern, and type of gene mutation according to gene alleles

\begin{tabular}{|c|c|c|c|c|}
\hline \multicolumn{4}{|c|}{ Gene mutation } & Frequency $(n=230)$ \\
\hline \multicolumn{4}{|c|}{ V726A } & $56(24.35 \%)$ \\
\hline \multicolumn{4}{|l|}{ E148Q } & $48(20.87 \%)$ \\
\hline \multicolumn{4}{|l|}{ M694I } & 47 (20.43\%) \\
\hline \multicolumn{4}{|l|}{ M680I } & $29(12.61 \%)$ \\
\hline \multicolumn{4}{|l|}{ M694V } & $24(10.43 \%)$ \\
\hline \multicolumn{4}{|l|}{ A7445 } & 7 (3.04\%) \\
\hline \multicolumn{4}{|l|}{ K695R } & $1(0.43 \%)$ \\
\hline \multicolumn{4}{|l|}{ 1692de1 } & $1(0.43 \%)$ \\
\hline \multicolumn{4}{|l|}{ S650F } & $1(0.43 \%)$ \\
\hline & \multicolumn{3}{|c|}{ Type of mutation } & \multirow{3}{*}{$\begin{array}{l}\text { Total } \\
(n=400)\end{array}$} \\
\hline & Heterozygous & Homozygous & Compound heterozygous & \\
\hline & Count $(\%)$ & Count $(\%)$ & Count $(\%)$ & \\
\hline V726A & $37(9.25 \%)$ & $6(1.50 \%)$ & 16 (4.00\%) & $59(14.75 \%)$ \\
\hline E148Q & 38 (9.50\%) & $2(0.50 \%)$ & $9(2.25 \%)$ & 49 (12.25\%) \\
\hline M694I & $18(4.50 \%)$ & $28(7.00 \%)$ & 15 (3.75\%) & $61(15.25 \%)$ \\
\hline M680I & $16(4.00 \%)$ & $14(3.50 \%)$ & $6(1.50 \%)$ & $36(9.00 \%)$ \\
\hline M694V & $11(2.75 \%)$ & $4(1.00 \%)$ & $11(2.75 \%)$ & $26(6.50 \%)$ \\
\hline A7445 & $5(1.25 \%)$ & $0(0 \%)$ & $2(0.50 \%)$ & $7(1.75 \%)$ \\
\hline K695R & $1(0.25 \%)$ & $0(0 \%)$ & $0(0 \%)$ & $1(0.25 \%)$ \\
\hline 1692de1 & $0(0 \%)$ & $0(0 \%)$ & $1(0.25 \%)$ & $1(0.25 \%)$ \\
\hline S650F & $1(0.25 \%)$ & $0(0 \%)$ & $0(0 . \%)$ & $1(0.25 \%)$ \\
\hline Total & $127(31.75 \%)$ & $54(13.5 \%)$ & 60 (15\%) & $241(60.25 \%)$ \\
\hline
\end{tabular}


Table 3 Comparison between group 1 and group 2 patients as regard to age, gender, consanguinity, disease duration, and family history showing results as $p$ value

\begin{tabular}{|c|c|c|c|c|}
\hline & & Group $1(n=41)$ & Group $2(n=159)$ & $P$ value \\
\hline \multirow[t]{2}{*}{ Gender $^{a}$} & $\mathrm{~F}$ & $18(43.9 \%)$ & $86(54.1 \%)$ & \multirow[t]{2}{*}{0.244} \\
\hline & M & $23(56.1 \%)$ & $73(45.9 \%)$ & \\
\hline Consanguinity $^{\mathrm{a}}$ & & $14(34.1 \%)$ & $54(34.0 \%)$ & 0.982 \\
\hline Age at time of study (years) ${ }^{c}$ & Mean \pm SD & $10.95 \pm 3.11$ & $9.73 \pm 3.53$ & 0.023 \\
\hline Age at onset of FMF (years) ${ }^{c}$ & Mean \pm SD & $3.48 \pm 2.27$ & $4.69 \pm 2.95$ & 0.031 \\
\hline Age at diagnosis(years) ${ }^{c}$ & Mean \pm SD & $5.46 \pm 2.65$ & $6.45 \pm 3.15$ & 0.113 \\
\hline Disease duration(years $)^{c}$ & Mean \pm SD & $7.48 \pm 2.88$ & $5.04 \pm 3.08$ & $<0.001$ \\
\hline Family history of FMF ${ }^{a}$ & & $15(36.6 \%)$ & $61(38.4 \%)$ & 0.834 \\
\hline Family history of other autoimmune disease ${ }^{b}$ & & $4(9.8 \%)$ & $22(13.8 \%)$ & 0.488 \\
\hline \multirow[t]{4}{*}{ Type of autoimmune disease in the family history ${ }^{b}$} & SLE & $0(0.0 \%)$ & $6(27.3 \%)$ & \multirow[t]{4}{*}{0.788} \\
\hline & Rheumatoid arthritis & $1(25.0 \%)$ & $5(22.7 \%)$ & \\
\hline & Rheumatic fever & $3(75.0 \%)$ & $8(36.4 \%)$ & \\
\hline & Type 1 DM & $0(0.0 \%)$ & $3(13.6 \%)$ & \\
\hline
\end{tabular}

$N$ number, SD standard deviation, FMF familial Mediterranean fever, SLE systemic lupus erythematosus, DM diabetes mellitus

${ }^{a}$ Chi-squared test

${ }^{\mathrm{b}}$ Fisher's exact test

${ }^{c}$ Mann-Whitney test

All our patients were on colchicine treatment only. Colchicine dosage was significantly higher in patients with arthritis.

Regarding severity score, severe disease was found in 53 patients (26.5\%), moderate disease was found in 35 patients (17.5\%), and mild disease severity was found in 112 patients (56\%). Regarding FMF-50 score for assessing response to colchicine treatment in FMF patients, it was found that 139 patients (69.5\%) had a good response to treatment while 61 patients $(30.5 \%)$ had a poor response to treatment. We increased the colchicine dosage to patients with poor response.

As regards joint involvement, it was monoarticular in 30 patients $(73.1 \%)$, oligoarticular in 9 patients $(22 \%)$, and polyarticular in only 2 patients $(4.9 \%)$; the knees were the most commonly affected and were found in 32 patients $(78 \%)$, followed by the ankles in 30 patients (73.2\%), wrist in 7 patients (17.1\%), hips in 4 patients

Table 4 Comparison between group 1 and group 2 patients as regards clinical features at the time of the study, laboratory parameters at the time of the disease diagnosis and colchicine dosage

\begin{tabular}{|c|c|c|c|}
\hline & Group $1(n=41)$ & Group $2(n=159)$ & $p$ value \\
\hline Fever $^{a}$ & $40(97.6 \%)$ & $144(90.6 \%)$ & 0.201 \\
\hline Chest pain $^{a}$ & $23(56.1 \%)$ & $47(29.6 \%)$ & 0.001 \\
\hline Abdominal pain ${ }^{a}$ & $40(97.6 \%)$ & $154(96.9 \%)$ & 1 \\
\hline Erythematous-like erythema ${ }^{a}$ & $9(22.0 \%)$ & $7(4.4 \%)$ & 0.001 \\
\hline Testicular affection ${ }^{b}$ & $6(26 \%)$ & $4(5.5 \%)$ & 0.006 \\
\hline $\mathrm{HSP}^{\mathrm{a}}$ & $3(7.3 \%)$ & $12(7.5 \%)$ & 1 \\
\hline $\mathrm{Hb}(\mathrm{mg} / \mathrm{dl})^{c}$ & $11.30 \pm 1.31$ & $11.67 \pm 1.29$ & 0.098 \\
\hline $\operatorname{TLC}(* 1000)^{\mathrm{C}}$ & $8.66 \pm 3.54$ & $8.56 \pm 3.57$ & 0.643 \\
\hline $\operatorname{PLT}(* 1000)^{c}$ & $360.20 \pm 92.51$ & $344.81 \pm 120.20$ & 0.206 \\
\hline $\mathrm{ESR}^{\mathrm{C}}$ & $45.10 \pm 29.35$ & $35.36 \pm 27.17$ & 0.028 \\
\hline $\mathrm{CRP}^{\mathrm{C}}$ & $26.72 \pm 17.50$ & $27.51 \pm 27.77$ & 0.591 \\
\hline Persistant proteinuria (frequency $\%)^{b}$ & $0(0.0 \%)$ & $1(0.6 \%)$ & 1 \\
\hline Colchicine dosage at time of study $(g)^{c}$ & $1.46 \pm 0.53$ & $1.13 \pm 0.45$ & $<0.001$ \\
\hline
\end{tabular}

$N$ number, HSP Henoch-Schonlein Purpura, Hb hemoglobin, $T L C$ total leucocytic count, $P L T$ platelet, ESR erythrocyte sedimentation rate, CRP C-reactive protein, $g$ gram

${ }^{\text {a } C h i-s q u a r e d ~ t e s t ~}$

${ }^{b}$ Fisher's exact test

'Mann-Whitney test 
(9.8\%), elbows in 4 patients (9.8\%), small joints of the feet in 2 patents $(4.9 \%)$, and small joints of the hands in 1 patient (2.4\%). No arthritis was observed outside the FMF attacks.

Clinical characteristics of the arthritic attacks in FMF arthritis patients were summarized in Table 5. The persistence of swelling after the attacks for 1-2 days was observed in 7 patients (17.1\%), and complete resolution without chronic limitation was observed in all our arthritic patients $(100 \%)$.

In our study, disease severity was found to be statistically significant higher in patients with arthritis $(p=$ 0.001), while no statistical difference as regards FMF $50 \%$ score (Table 6).

The type of gene mutation of FMF patients with arthritis was summarized in Table 7.

\section{Discussion}

We found that $20 \%$ of the studied group had arthritis during their FMF attacks. Joint involvement was mostly mono-articular and non-erosive, affecting predominantly the large joints of the lower limbs. Disease severity was higher in patients with arthritis.

We found that the mean age of FMF disease onset was significantly lower in arthritic group, and the mean disease duration was significantly longer in arthritic group. This comes lower than the mean age of onset of FMF reported by Ince et al. 2002 and Jarjour and Dodaki 2011, and similar to Majeed and Rawashdeh 1997 [16, 23, 24]. Arthritis and early disease onset were linked together in other studies [18, 25].

When we analyzed the clinical presentation, we found that abdominal pain was the most common followed by fever, chest pain, and arthritis. This is similar to the results of another Egyptian study [26], while Duşunsel

Table 5 Clinical characteristics of the arthritic attacks in FMF arthritis patients and response to colchicines treatment

\begin{tabular}{ll}
\hline Arthritis characteristics & $\begin{array}{l}\text { Frequency } \\
(\boldsymbol{n}=\mathbf{4 1}) \%\end{array}$ \\
\hline Fever & $31(75.6 \%)$ \\
Redness & $29(70.7 \%)$ \\
$\begin{array}{l}\text { Limitation of joint movement during } \\
\text { the attack }\end{array}$ & $41(100 \%)$ \\
$\begin{array}{l}\text { Persistence of joint swelling for } \mathbf{2} \\
\text { days after the attack }\end{array}$ & $7(17.1 \%)$ \\
Resolution without chronic limitation & $41(100 \%)$ \\
Response of arthritis attacks to colchicine & \\
$75-100 \%$ decrease in the frequency & $85.4 \%$ \\
$50 \%$ decrease in the frequency & $9.8 \%$ \\
$25 \%$ decrease in the frequency & $4.8 \%$ \\
\hline
\end{tabular}

$N$ number et al. [27] reported that fever was the most common followed by abdominal pain. It seems that different genetic patterns of the disease among different populations affect the clinical picture of the attacks.

Heterozygous mutation was the most frequent genetic pattern, followed by compound heterozygous and homozygous mutation. The Lebanese study by Mneimneh et al. [28] reported similar results. High rate of simple heterozygosity in an autosomal dominant disease may suggest the presence of one or more modifying alleles or other environmental factors [diet, temperature, oxygen levels, humidity, light cycles, and presence of mutagens can impact on which gene is expressed] which eventually affect phenotype [29].

The most frequent MEFV gene mutations were V726A (24.35\%), E148Q (20.87\%), M694I (20.43\%), M680I (12.61\%), M694V (10.43\%), and A7445 (3.04\%). This is nearly similar to many studies $[26,27]$ while in the study by Mneimneh et al. [28], M694V (37.2\%) and E148Q (27.4\%) were the commonest. These differences may be due to the effect of different genetic backgrounds that affect the genetic pattern of the disease.

According to Mor et al. 2005's severity score [20], nearly half of the patients (56\%) had mild disease, $17.5 \%$ had moderate, and $26.5 \%$ had severe disease. This is nearly similar to the Turkish studies [30, 31]. On the other hand, Lotfy et al. [32] used Pras severity score [33] and reported more severe courses (63.5\% severe cases). These differences may be due to the use of different severity scores.

On following response to colchicine, $69.5 \%$ were good responders and $30.5 \%$ were poor responders. In other studies, Mneimneh et al. [28] reported a complete response in $33.3 \%$, incomplete response in $52.2 \%$, and no response in $14.5 \%$. Barutet al [34]. reported a complete response in $79 \%$. Different response to treatment may be affected by the genetic background of the disease.

We observed arthritis in 41 patients (20.5\%). This is nearly similar to some Egyptian studies [32, 35]. However, other studies as Salah et al. [36], El-Garf et al. [23], Yilmaz et al. [31], and Barut et al. [34] reported a higher frequency of arthritis (ranging from 42 to 57\%).

We found the mean age at arthritis onset to be $5.72 \pm$ 2.67 years. This is similar to Majeed and Rawashdeh [23], but lower than Ince et al.'s [24]. The mean duration of the attacks of arthritis in this study was $110.05 \pm 50.9$ $h$. The duration of the attacks of arthritis reported by Ince et al. [24] ranged from $12 \mathrm{~h}$ to 6 weeks.

Arthritis was the presenting symptom in $4 \%$. This is nearly similar to Karakayalı et al. [37]. Monoarticular arthritis was the commonest type, followed by oligoarticular and polyarticular types. This is nearly similar to most of the studies done [24, 38], except for Jarjour and 
Table 6 Comparison between group 1 and group 2 patients as regards severity score, FMF 50\% score

\begin{tabular}{lllll}
\hline & & Group 1 $(\boldsymbol{n}=\mathbf{4 1})$ & Group 2 $(\boldsymbol{n}=\mathbf{1 5 9 )}$ & $\boldsymbol{p}$ value \\
\hline Severity score $^{\mathrm{a}}$ & Mild & $11(26.8 \%)$ & $101(63.5 \%)$ & $26(16.4 \%)$ \\
& Moderate & $9(22.0 \%)$ & $32(20.1 \%)$ \\
FMF 50\% score & Severe & $21(51.2 \%)$ & $109(68.6 \%)$ & 0.567 \\
& Good responders & $30(73.2 \%)$ & $50(31.4 \%)$ \\
\hline
\end{tabular}

$N$ number

${ }^{\mathrm{a} C h i}$-squared test

Dodaki [16], who found a more prevalence to di-arthritis pattern.

We observed that the knees were the most affected joint, followed by the ankles, wrists, hips, and elbows. We did not find axial or tempromandibular joint affection. This is nearly similar to the study done by Jarjour and Dodaki [16].

We found that fever, redness, and limitation of movement of the affected joint, joint swelling for 1-2 days followed by a complete resolution of arthritis were common findings in arthritis attacks. This is nearly similar to all studies as Ince et al. [24]. None of the patients developed irreversible joint damage.

We found that the most frequent MEFV gene mutations were V726A, E148Q, M694I, M680I, and M694V. In Jarjour and Dodaki [16] study, the most frequent mutations were M694V followed by M694I. This difference suggests a unique genetic background for each population.

Disease severity was found to be higher in patients with arthritis $(p=0.001)$. Also, arthritis was more prevalent in patients with higher disease severity $(p=0.0004)$. This was a common finding with Eshed et al. [10].

The frequency of erysipelas-like erythema in patients with arthritis was $22 \%$ in the present study, with a statistical significance difference. This comes in agreement with Ince et al., who reported that ELE was an associated finding to arthritis in the lower limbs [31]. Also, chest pain and testicular affection were statistically higher in patients with arthritis, together with ESR at time of

Table 7 Type of gene mutation of FMF patients with arthritis ( $n$ $=49$ )

\begin{tabular}{ll}
\hline Frequency $(\boldsymbol{n}=\mathbf{4 9})$ & Gene mutation \\
\hline V726A & $14(28.6 \%)$ \\
E148Q & $14(28.6 \%)$ \\
M694I & $10(20.4 \%)$ \\
M680I & $5(10.2 \%)$ \\
M694V & $4(8.2 \%)$ \\
Negative gene mutation & $2(4.0 \%)$ \\
\hline
\end{tabular}

$N$ number diagnosis. These findings may be linked to a higher disease severity with these symptoms.

The limitation of the study was the relatively small number of patients included in the study and the need for the cooperation of more than one center in data collection.

\section{Conclusion}

Frequency of arthritis in Egyptian children with FMF can be estimated to be around $20 \%$. Joint affection was mostly mono-articular and non-erosive, affecting predominantly the large joints of the lower limbs. Disease severity was higher in patients with arthritis. Studies with a larger number of patients are recommended to verify these findings.

\section{Abbreviations \\ FMF: Familial Mediterranean fever; MEFV: Mediterranean fever gene}

\section{Acknowledgements}

We are very grateful to the nurses and the secretary in our clinic, who work hard to organize and facilitate our work.

\section{Authors' contributions}

All authors have contributed significantly and all authors are in agreement with the content of the manuscript. YM contributed to the searching of literature, writing and editing the manuscript, and being the corresponding author. HT contributed to following the results and writing the manuscript. NMS contributed to the idea of the research, following the results, and writing the manuscript. DF contributed to the searching of literature, collecting the data, performing the statistical part of the research, and writing the manuscript. HM contributed to following the results and writing the manuscript. The authors read and approved the final manuscript.

Funding

No funding was obtained for this study.

\section{Availability of data and materials}

The dataset used and/or analyzed during the current study are available with the corresponding author on reasonable request.

Ethics approval and consent to participate

This study was approved by the ethical scientific committee of the Faculty of Medicine, Cairo University (reference number: 1-210317). Written informed consents to participate were taken from the parents or the patient's legal guardian.

Consent for publication

Written informed consents to publish the data contained within this study were taken from the parents or the patient's legal guardians. 


\section{Competing interests}

The authors declare that they have no competing interests.

Received: 16 July 2020 Accepted: 19 November 2020

Published online: 11 December 2020

\section{References}

1. Soliani M, Cattalini M, Vitale A, Sota J, Cantarini L (2018) Musculoskeletal manifestations in hereditary periodic fever syndromes. Clin Exp Rheumato 36(suppl 110):525-531

2. Ozen S, Bilginer $Y$ (2014) A clinical guide to autoinflammatory diseases. Familial Mediterranean fever and next -of-kin. Nat Rev Rheumatol 10: 135-147

3. Lidar M, Livneh A (2007) Familial Mediterranean fever: clinical, molecular and management advancements. Neth J Med 65:318-324

4. Onen F (2006) Familial Mediterranean fever. Rheumatol Int 26:489-496

5. Migita K, Abiru S, Sasaki O, Miyashita T, Izumi Y, Nishino A (2014) Coexistence of familial Mediterranean fever and rheumatoid arthritis. Mod Rheumatol 24(1):212-216

6. Federici S, Calcagno G, Finetti M et al (2012) Clinical impact of MEFV mutations in children with periodic fever in a prevalent western European Caucasian population. Ann Rheum Dis 71(12):1961-1965

7. Shohat M, Halpern GJ (2011) Familial Mediterranean fever - a review. Genet Med 13(6):487-498

8. Heller H, Gafni J,Michaeli D, Shatin N, Sohar E,Ehrlich G, Karten I and Sokoloff $\mathrm{L}$. The arthritis of familial Mediterranean fever (FMF). Arthritis Rheum 1966;9:1-17.

9. Livneh A, Langevitz P (2000) Diagnostic and treatment concerns in Familial Mediterranean fever. Baillierses Best Pract Res Clin Rheumatol 14:477-498

10. Eshed I, Rosman Y, Livneh A et al (2014) Exertional leg pain in familial Mediterranean fever: a manifestation of an underlying enthesopathy and a marker of more severe disease. Arthritis Rheum 66(11):3221-3226

11. Yu JW, Wu J, Zhang Z (2006) Cryopyrin and pyrin activate casppase-1, but not NF-KappaB, via ASC oligomerization. Cell Death Differ 13(2):236-249

12. Ekinci Z (2012) Musculoskeletal symptoms in familial Mediterranean fever. Ann Pediatr Rheum 3:156-162

13. Ureten K, Gönülalan G, Akbal E, Günes F, Akyürek O, Ozbek M (2010) Demographic, clinical and mutational characteristics of Turkish familial Mediterranean fever patients: results of a single center in Central Anatolia. Rheumatol Int 30:911-915

14. Horovitz Y, Tanous O, Khayat M, Shaker M, Shalev S, Spiegel R (2016) Diagnosis of familial Mediterranean fever following the initial presentation of monoarthritis. Int J Rheum Dis 21(3):755-760

15. Shinawi M, Brik R, Berant M, Kasinetz L, Gershoni-Baruch R (2000) Familial Mediterranean fever: high gene frequency and heterogeneous disease among an Israeli-Arab population. J Rheumatol 27:1492-1495

16. Jarjour RA, Dodaki R (2011) Arthritis patterns in familial Mediterranean fever patients and association with M694V mutation. Mol Biol Rep 38:2033-2036

17. EL-Shanti H, Majeed HA, EL-Khateeb M (2006) Familial Mediterranean fever in Arabs. Lancet 367:1016-1024

18. Bilgen SA, Kilic L, Akdogan A, Kiraz S, Kalyoncu U, Karadag O, Ertenli I, Dogan I, Calguneri M (2011) Effects of anti-tumor necrosis factor agents for familial Mediterranean fever patients with chronic arthritis and/or sacroiliitis who were resistant to colchicine treatment. J Clin Rheumatol 17(7):358-362.

19. Yalcinkaya F, Ozen S, Ozcakar ZB, Aktay N, Cakar N, Düzova A (2009) A new set of criteria for the diagnosis of familial Mediterranean fever in childhood. Rheumatology (Oxford) 48:395-398

20. Mor A, Shinar Y, Zaks N et al (2005) Evaluation of disease severity in familial Mediterranean fever. Semin Arthritis Rheum 35(1):57-64

21. Chan YH (a). Biostatistics 102: Quantitative Data- parametric and nonparametric tests. Singapore medical journal 2003:44:391-6.

22. Chan YH (b). Biostatistics 103: Qualitative data-tests of Independence. Singapore medical journal 2003b;44:498-503.

23. Majeed HA, Rawashdeh M (1997) The clinical patterns of arthritis in children with familial Mediterranean fever. Q J Med 90:37-43

24. Ince $\mathrm{E}$, Tekin M, Kendirli T, Ozkaya N, Akar N (2002) Arthritis in children with familial Mediterranean fever. Rheumatol Int 21:213-217

25. HafizeEmineSonmez HE, Esmeray P, Batu ED, Arıcı ZS, Demir S, Sağ E, Ozen S, Bilginer $Y$ (2019) Is age associated with disease severity and compliance to treatment in children with familial Mediterranean fever? Rheumatol Int 39(1):83-87
26. Lofty HM, Marzouk H, Farag Y, Nabih M, Khalifa IA, Mostafa N, Salah A Rashed L, El Garf K.Int J Rheumatol. 2016;2016:7354018. https://doi.org/10. 1155/2016/7354018

27. Dusunsel R, Dursun I, Gündüz Z, Poyrazoglu MH, Gürgöze MK, Dundar M (2008) Genotype - phenotype correlation in children with familial Mediterranean fever in a Turkish population. Pediatr Int 50:208-212

28. Mneimneh S, Naous A, Naja Z et al (2016) Familial Mediterranean fever: clinical and genetic characteristics among Lebanese pediatric population. Open J Rheumatol Autoimmune Dis 6:63-73

29. Ben-Zvi I, Brandt B, Berkun Y, Lidar M, Livneh A (2012) The relative contribution of environmental and genetic factors to phenotypic variation in familial Mediterranean fever (FMF). Gene 491(2):260-263

30. Kilic A, Varkal MA, Durmus MS et al (2015) Relationship between clinical findings and genetic mutations in patients with familial Mediterranean fever. Pediatr Rheumatol 12:13-59

31. Yilmaz R, Karaaslan E, Ozer S et al (2014) Hypovitaminosis D in children with familial Mediterranean fever. Clin Invest Med 37:E211-E216

32. Lotfy HM, Marzouk H, Farag $Y$ et al (2017) Serum vitamin D level in Egyptian children with familial Mediterranean fever. Immunol Lett 185:74-78

33. Pras E, Livneh A, Balow JE et al (1998) Clinical differences between North African and Iraqi Jews with familial Mediterranean fever. Am J Med Genet 75(2):216-219

34. Barut K, Sahin S, Adrovic A, Sinoplu AB, Yucel G, Pamuk G (2018) Familial Mediterranean fever in childhood: a single-center experience. Rheumatol Int 38(1):67-74

35. Settin A, El-Baz R, AbdRasool M, El-Khalegy H, El-Sayed O, El-Bendary M (2007) Clinical and molecular diagnosis of familial Mediterranean fever in Egyptian children. J Gastrointestin Liver Dis 16:141-145

36. Salah S, Talaat HS, El Basha NR, Marzouk H, AbdElhamid S, Shafie ES (2017) Comparing D-dimer status in children with familial Mediterranean fever during and in between acute attacks. Egypt Rheumatol 40(2):107-110

37. Karakayalı A, Erten S, Akan S et al (2017) Demographic, clinical and genetic features of the patients with familial Mediterranean fever. J Clin Anal Med 8(1):1-5

38. Uthman I, Hajj-Ali RA, Arayssi T, Masri AF, Nasr F (2001) Arthritis in familial Mediterranean fever. Rheumatol Int 20:145-148

\section{Publisher's Note}

Springer Nature remains neutral with regard to jurisdictional claims in published maps and institutional affiliations.

\section{Submit your manuscript to a SpringerOpen ${ }^{\circ}$ journal and benefit from:}

- Convenient online submission

- Rigorous peer review

- Open access: articles freely available online

- High visibility within the field

- Retaining the copyright to your article

Submit your next manuscript at $>$ springeropen.com 